\title{
Irradiation Performance of U-Mo Alloy Based 'Monolithic' Plate-Type Fuel - Design Selection
}

\author{
A.B. Robinson \\ G.S. Chang \\ D.D. Keiser, Jr. \\ D.M. Wachs \\ D.L. Porter
}

August 2009

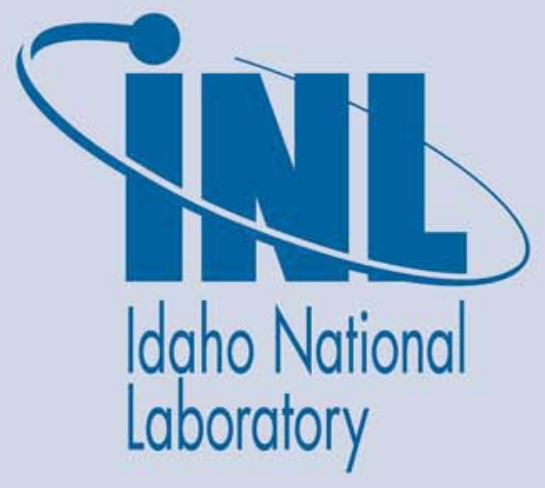

The INL is a U.S. Department of Energy National Laboratory operated by Battelle Energy Alliance 
INL/EXT-09-16807

\title{
Irradiation Performance of U-Mo Alloy Based 'Monolithic' Plate-Type Fuel - Design Selection
}

\author{
A.B. Robinson \\ G.S. Chang \\ D.D. Keiser, Jr. \\ D.M. Wachs \\ D.L. Porter
}

August 2009

\section{Idaho National Laboratory \\ Idaho Falls, Idaho 83415}

http://www.inl.gov 


\section{DISCLAIMER}

This information was prepared as an account of work sponsored by an agency of the U.S. Government. Neither the U.S. Government nor any agency thereof, nor any of their employees, makes any warranty, expressed or implied, or assumes any legal liability or responsibility for the accuracy, completeness, or usefulness, of any information, apparatus, product, or process disclosed, or represents that its use would not infringe privately owned rights. References herein to any specific commercial product, process, or service by trade name, trade mark, manufacturer, or otherwise, does not necessarily constitute or imply its endorsement, recommendation, or favoring by the U.S. Government or any agency thereof. The views and opinions of authors expressed herein do not necessarily state or reflect those of the U.S. Government or any agency thereof. 



\section{Irradiation Performance of U-Mo Alloy Based 'Monolithic' Plate-Type Fuel - Design Selection}

INL/EXT-09-16807

Revision 0

August 2009

Approved by:

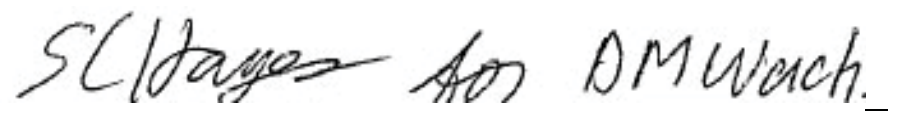

Daniel M. Wachs

August 25, 2009

Date 



\begin{abstract}
A down-selection process has been applied to the U-Mo fuel alloy based monolithic plate fuel design, supported by irradiation testing of small fuel plates containing various design parameters. The irradiation testing provided data on fuel performance issues such as swelling, fuel-cladding interaction (interdiffusion), blister formation at elevated temperatures, and fuel/cladding bond quality and effectiveness. U-10Mo (wt \%) was selected as the fuel alloy of choice, accepting a somewhat lower uranium density for the benefits of phase stability. U-7Mo could be used, with a barrier, where the trade-off for uranium density is critical to nuclear performance. A zirconium foil barrier between fuel and cladding was chosen to provide a predictable, well-bonded, fuel-cladding interface, allowing little or no fuel-cladding interaction. The fuel plate testing conducted to inform this selection was based on the use of U-10Mo foils fabricated by hot co-rolling with a $\mathrm{Zr}$ foil. The foils were subsequently bonded to Al-6061 cladding by hot isostatic pressing or friction stir bonding.
\end{abstract}




\section{CONTENTS}

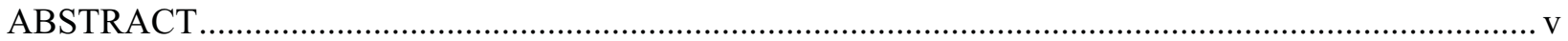

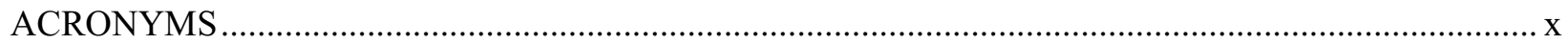

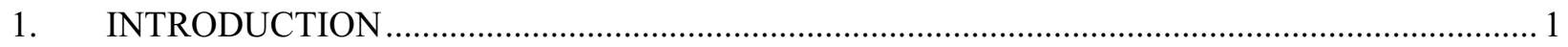

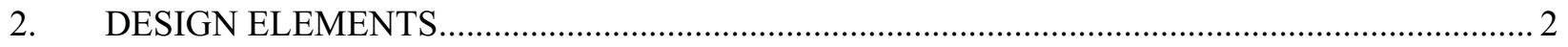

3. IRRADIATION TESTING OF VARIOUS DESIGN ELEMENTS …..................................... 3

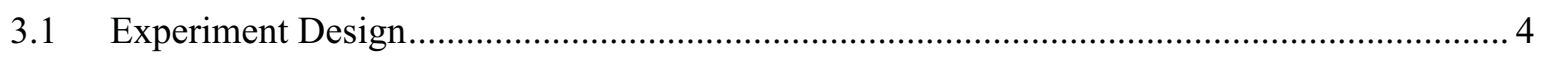

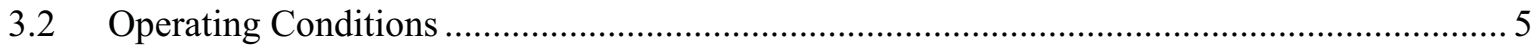

3.3 Post-irradiation Examination Results from the Early Experiments (RERTR-4,

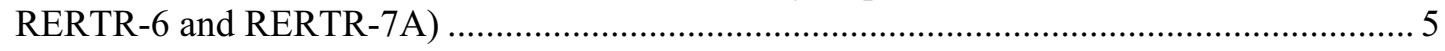

3.4 RERTR-8: Inclusion of Hot Isostatic Pressing …............................................................. 7

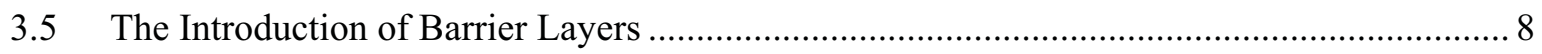

3.6 RERTR-9 and RERTR-10: Testing of the Primary Design Options................................... 9

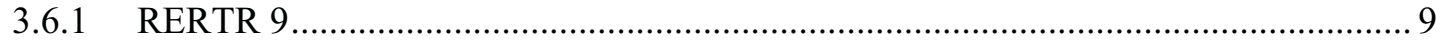

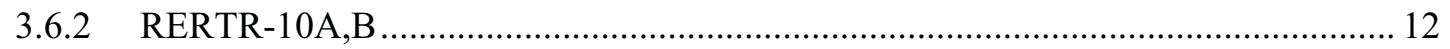

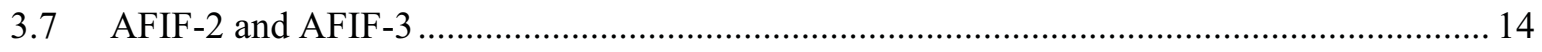

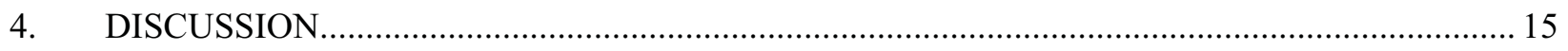

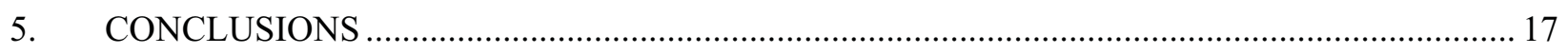

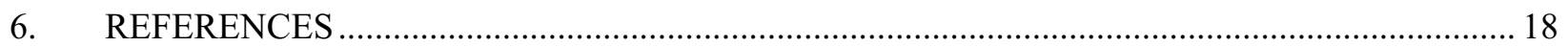

\section{FIGURES}

Figure 1. Sketch of RERTR Test Mini-plate (monolithic fuel). .......................................................... 4

Figure 2. Bubble formation in the interaction layer between a U-10Mo foil and Al-6061 ........................ 6

Figure 3. RERTR-8 monolithic fuel swelling as measured by plate thickness change. ${ }^{23}$.......................... 7

Figure 4. Optical image of metallographic section of monolithic fuel plate from RERTR-8 (U-

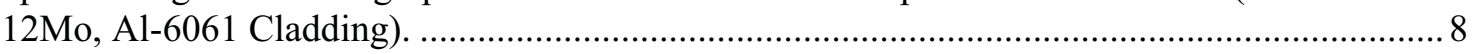

Figure 5. Optical micrograph of RERTR-9 test plate cross-section, which had an inner Al-4043 clad interface.

Figure 6. Optical micrograph of RERTR-9 test plate cross-section, which had an Inner Al-4043 clad interface on one surface (lower edge in photo) and Al-6061 on the other........................ 10

Figure 7. Optical micrograph of an RERTR-9 fuel plate cross-section ('cold' side). .............................. 11

Figure 8. Optical micrograph of an RERTR-9 fuel plate cross-section ('hot' side). The fuel foil has cracked but the cracks do not propagate along or through the fuel/Zr boundary. 
Figure 9. Average swelling (thickness increase) of a fuel plate. Variables are shown in legend. Those labels indicating two variables, e.g., $1.5 / 2 \% \mathrm{Si}$, one relates to the coating on one side of the plate and the other for the opposite side

Figure 10. Optical metallography of an RERTR-10A fuel plate, co-rolled with Zr foil barriers and HIP processed. Only a small amount of porosity/bubble formation is visible at the $\mathrm{Zr}$ fuel boundary.

\section{TABLES}

Table 1. Fuel design variables tested for monolithic plates. 3

Table 2. Operating conditions of RERTR test fuel plates (monolithic fuel). 


\section{ACRONYMS}

AFIP $\quad \underline{A} T R$ Full-size-plate $\underline{I n}$ center flux trap $\underline{\text { Position }}$

ATR Advanced Test reactor

FB Friction Bonding

FSW friction stir welding

HEU Highly Enriched Uranium

HIP Hot Isostatic Press

LEU low enriched uranium

LTA Lead Test Assembly

RERTR Reduced Enrichment for Research and Test Reactors

TLPB Transient Liquid Phase Bonding 


\section{Irradiation Performance of U-Mo Alloy Based 'Monolithic' Plate-Type Fuel - Design Selection}

\section{INTRODUCTION}

For over 30 years the Reduced Enrichment for Research and Test Reactors (RERTR) program has worked to provide the fuel technology and analytical support required to convert research and test reactors from nuclear fuels that utilize highly enriched uranium (HEU) to fuels based on low enriched uranium (LEU) (defined as $<20 \% \mathrm{U}-235$ ). While many of these reactors could be converted using LEU nuclear fuels based upon traditional dispersion type fuel designs including $\mathrm{U}_{3} \mathrm{Si}_{2}$ or U-Mo alloy fuel particles in an aluminum based matrix, some reactors were identified that could only be converted using LEU fuel of a significantly modified design. The uranium density would have to be higher than reasonably achievable in dispersion fuels. ${ }^{1}$

The design chosen was a new very high density plate-type nuclear fuel, using a U-Mo alloy fuel foil sealed in aluminum alloy cladding. Development of this design was initiated by the RERTR program as a way to significantly increase the maximum uranium density of research and test reactor fuel. ${ }^{2}$ This design was identified as the 'monolithic' fuel design, which referred to the solid U-Mo alloy fuel meat. This general type of fuel meat configuration had already been tested with rod-type fuel in order to minimize the fuel interaction with the matrix material in dispersion fuel designs. ${ }^{3}$

The RERTR Advanced Fuel Development program has been tasked with the development of this fuel which includes the development of an appropriate fuel system and design, development of fabrication technology for that fuel, establishing the fuel behavior and performance parameters, conducting fabrication technology development and demonstration, supporting the scale-up and transfer of fabrication technology and the supply of test assemblies, and to provide fuel design and licensing support for conversion.

The program has executed a wide array of fuel tests over the last decade that clearly established the viability of research reactor fuels based on uranium-molybdenum (U-Mo) alloys. The monolithic fuel design represents a more significant departure from existing technology in that the entire fuel meat zone is replaced by the U-Mo alloy. This modification poses some unique fabrication challenges that must be resolved as part of the performance evaluation. New variables introduced by these fabrication techniques and the design of the fuel plate has required an experimental irradiation program with wide scope to help down-select the fabrication method options, fuel alloy, and fuel/cladding barrier options.

It is the purpose of this report to review the irradiation test results to date and outline the observations considered significant in providing information for the down-selection process. 


\section{DESIGN ELEMENTS}

The overarching development goal for the monolithic fuel design was to identify a fuel that would provide higher uranium density compared to the dispersion fuel design while simultaneously delivering comparable fuel performance.

Elements of the fuel plate design important to the fuel performance include:

1. Maintaining a good bond between the fuel meat and the aluminum-based cladding. Gap formation can create a situation for poor thermal transfer and fission gas may collect in that location promoting further separation, plate bulging, and subsequent coolant channel gap closure. Formation of bulges (or blisters) may also result in fission gas release from the plates.

2. Minimizing fuel/cladding chemical interaction. The interaction layer (IL) that can form between the Al-6061 cladding and U-Mo fuel is similar to that observed at the fuel/matrix interface in dispersion fuels. The interaction layer typically consists of intermetallic phases that may have poor mechanical properties (e.g., brittle $)^{4}$ and be susceptible to breakaway swelling. ${ }^{5}$ In some cases alloying additions to cladding/matrix materials seems to minimize the viscosity degradation of the interaction layer and, presumably, delay or eliminate the onset of breakaway swelling. ${ }^{6}$

3. Providing a fabrication process that is easily repeatable and amenable to a number of different fuel plate geometries. This includes the need in some cases to incorporate a burnable poison into the fuel design $^{7}$ and potentially other new design features required to meet the other design elements mentioned above. The testing to date has not been focused on the issues of 'complex' fuel fabrication although care has been taken to consider the potential for extrapolation of the selected fuel designs and fabrication processes in the down-selection process.

The fabrication development aspect of the RERTR efforts is beyond the scope of this paper, but the development of fabrication methods currently being tested to provide support for down-selection of specific design elements can be traced in a number of documents. ${ }^{8,9,10,11,12,13}$ There are also descriptions of other efforts published in this same time period outlining fabrication methods and product development performed by others in the U.S. and elsewhere. ${ }^{14,15,16,17}$

It is the intent to present in this document the irradiation testing results pertinent to current probable down-selection of monolithic fuel plate design. 


\section{IRRADIATION TESTING OF VARIOUS DESIGN ELEMENTS}

Many concepts were considered in order to improve the early monolithic fuel plate designs. A sampling of these variations included:

- Increasing the Mo concentration from 7 or $8 \mathrm{wt} \%$ to 10 or $12 \mathrm{wt} \%$ to simultaneously simplify foil fabrication and to provide additional stability to the gamma phase in the fuel and reduce fuel/cladding interaction and the resulting IL thickness.

- Insertion of a barrier material between the fuel and cladding. The barrier was used to either prevent diffusion between the cladding and fuel or to modify the composition of the interaction product such that it was stable under irradiation.

- Variation in fuel/clad bonding technology. The quality of the fuel/clad bond, fuel plate residual stresses, and fuel/clad interface chemical condition can be greatly influenced by the bonding technique employed.

The process used to fabricate fuel plates can play an integral role in the performance of the fuel design during irradiation. The fuel plates irradiation tested within this development program are typically fabricated by casting a U-Mo alloy ingot (through arc-melting or induction melting) in a book mold. The thin ingot is subsequently hot-rolled to an intermediate thickness. The ingot is then either cold rolled into a foil or hot rolled with the diffusion barrier (to allow for bonding). Silicon barrier coatings between fuel foil and cladding were also applied by thermal spray coating or by the insertion of a silicon rich aluminum alloy during fuel/clad bonding. The fuel/clad bonding fabrication techniques explored were hot isostatic pressing (HIP), friction bonding (FB) (previously referred to as friction stir welding [FSW]), and transient liquid phase bonding (TLPB). The TLPB bonding process is based on applying a Si spray coating to the fuel/clad interface and hot pressing the assembly a temperature above the Si-Al eutectic temperature $\left(577^{\circ} \mathrm{C}\right)$, leading to a diffusion bond between the two materials.

A series of six mini-plate experiments (RERTR-4, -6, -7A, -8, -9, and -10) and two full-size plate experiments (AFIP-2 and -3) were conducted in the Advanced Test Reactor to evaluate monolithic fuel performance over the last several years. A brief summary of the variations in the fuel design and fabrication techniques that were tested as part of the RERTR monolithic fuel development irradiation test plan are outlined in Table 1. The final down selection of design variables is a direct outcome of the observed results from these tests.

Table 1. Fuel design variables tested for monolithic plates.

\begin{tabular}{|l|c|c|c|c|}
\hline $\begin{array}{c}\text { Fuel Composition, } \\
\text { wt \% }\end{array}$ & $\begin{array}{c}\text { Fuel Foil } \\
\text { Thickness, } \mathrm{mm}\end{array}$ & Bond Type & Barrier & Other \\
\hline U-7Mo & 0.25 & FB & Zr Foil & Split Foil \\
\hline U-8Mo & 0.51 & HIP & Si spray coating & Holed Foil \\
\hline U-10Mo & 0.33 & TLPB & Al-4043 foil & Zry Cladding \\
\hline U-12Mo * & & Nb Foil & \\
\hline \multicolumn{5}{|r|}{} \\
\hline * Limited testing, as U-10Mo provides adequate phase stability, and allows for increased U density.
\end{tabular}




\subsection{Experiment Design}

The experiments of interest include the RERTR-4 test, in which two small fuel plates, each containing thin discs of U-10 Mo of $\sim 12-\mathrm{mm}$ diameter and $0.25-\mathrm{mm}$ thickness were irradiation tested. The irradiation stability (defined as the absence of breakaway swelling) observed in the RERTR-4 test encouraged further testing of the monolithic fuel plate design. ${ }^{18}$

The subsequent RERTR-6 irradiation test included both U-7Mo and U-10Mo based monolithic miniplates with foil thicknesses of $0.25 \mathrm{~mm}$ and $0.51 \mathrm{~mm}$. The foil dimensions were increased in size from the original small discs in RERTR-4 to the more representative dimensions shown in. Bonding of the fuel/clad interface in all the fuel plates was accomplished using friction bonding (FB). This test plate configuration was used for the remainder of the mini-plate test programs described in this report. The mini-plates were irradiated to fission densities consistent with roughly $50 \% \mathrm{U}-235$ burnup. All plates showed generally good irradiation behavior.

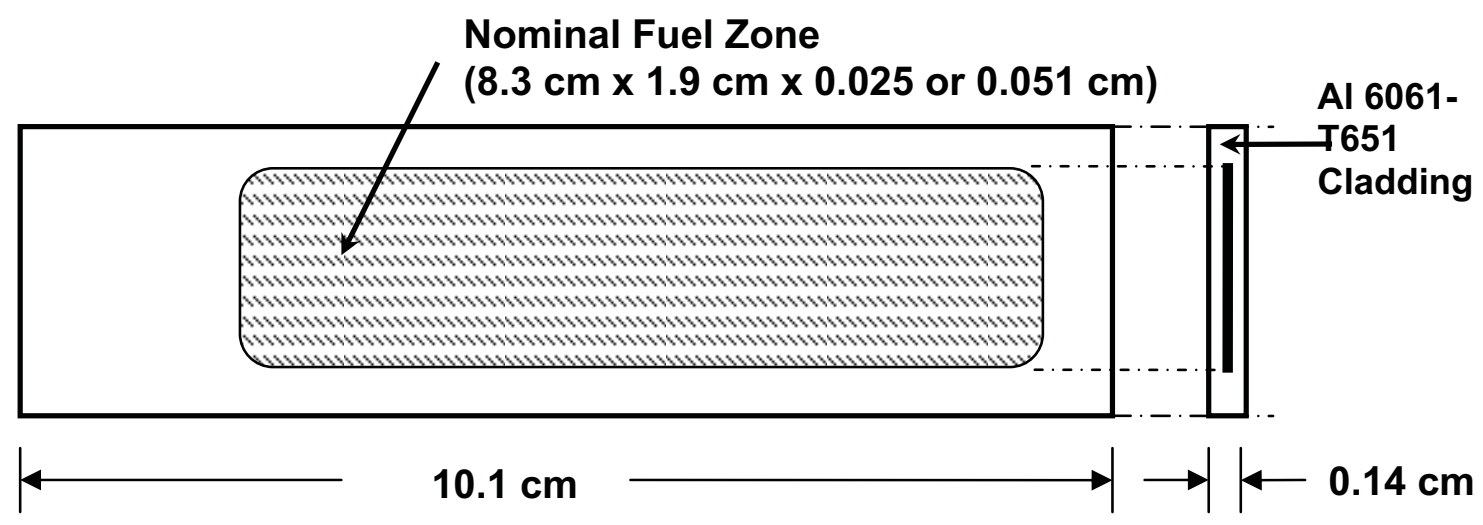

Figure 1. Sketch of RERTR Test Mini-plate (monolithic fuel).

Based on the success of the RERTR-6 experiments, many more monolithic fuel plates were incorporated into the RERTR-7A test. Difficulty fabricating low Mo alloy foils lead to the RERTR-7A experiment focusing on U-10Mo and U-12Mo. Otherwise, the mini-plates were similar to those tested in the RERTR-6 experiment (e.g., the same variations in thickness and bonding by FB). Because the life-limiting fuel performance phenomena were not apparent at low-power and burnup, the peak heat fluxes (and concomitant operating temperatures), and the peak fission density $/{ }^{235} \mathrm{U}$ depletion were increased for the RERTR-7A experiment and the tests that followed. In addition the standard monolithic fuel designs, two Zircaloy-4-clad (hot rolled) U-7Mo fuel plates were included. These were manufactured in Argentina at the Centro Atómico Constituentes ${ }^{15}$. Selected post-irradiation examination results for RERTR-6 and RERTR-7 have been previously reported. ${ }^{19}$ The RERTR- 8 experiment was similar to the RERTR-7 experiment. The test matrix incorporated U-8Mo, U-10Mo and U-12Mo fuel foils and fuel/clad bonding by HIP and FB. All foils were $0.25 \mathrm{~mm}$ thick.

The RERTR-9 experiment focused on monolithic fuel plates using only U-10Mo foils. Fuel plates fabricated by FB and HIP bonding were both represented. However, the key design variable consisted of the incorporation of barriers between the fuel foil and cladding. The barriers were inserted to prevent diffusion between the fuel and cladding ( $\mathrm{Zr}$ ) or to modify the chemistry of the formed interaction layer (Si). Barriers types included Zr, Al-4043 Al and Si-Al. 
The fuel plates tested in RERTR-10A experiment were all fabricated by HIP and were designed to more completely evaluate (1) the effect of various silicon compositions within the interlayer and (2) the thickness of the zirconium interlayer using $0.25 \mathrm{~mm}$ and $0.51 \mathrm{~mm}$ nominal foil thicknesses. The fuel plates in RERTR-10B were fabricated by friction bonding with two different thickness silicon layers and with niobium or zirconium diffusion barriers. The experiments were also used to test the role of fission rate, operating temperature, and fission density on fuel performance.

\subsection{Operating Conditions}

Table 2 shows the various thermal and nuclear conditions used for each of the tests. For all of these tests (except RERTR-6) the long edges of the fuel plates was oriented towards core center, creating a large gradient in fission/heating rate and fission density from one edge of the fuel zone to the other. The gradients provided for a more aggressive environment to test fuel performance as the gradients can induce large, non-uniform thermal and mechanical stresses, etc. on the fuel/cladding interfaces. These gradients are not reflected in the fission densities and rates, or in the heat fluxes listed in Table 2. Note however, the range of peak fuel temperatures. This represents the hottest fuel plate, and the low and high temperature represent the operating conditions at the edge facing away from the core and the edge facing the core center, respectively.

Table 2. Operating conditions of RERTR test fuel plates (monolithic fuel).

\begin{tabular}{|c|c|c|c|c|c|c|c|}
\hline \multirow[b]{2}{*}{ Fuel Test } & \multicolumn{2}{|c|}{$\begin{array}{l}\text { Plate Average* } \\
\text { Fission Density } \\
(\mathrm{Fd}), 10^{21} \mathrm{f} / \mathrm{cm}^{3}\end{array}$} & \multicolumn{2}{|c|}{$\begin{array}{c}\text { Plate Average* } \\
\text { Fission Rate, } 10^{14} \\
\mathrm{f} / \mathrm{cm}^{3} \cdot \mathrm{s}\end{array}$} & \multicolumn{2}{|c|}{$\begin{array}{l}\text { Plate Avg.* Heat } \\
\text { Flux, W/cm }{ }^{2} \\
\text { (hottest cycle) }\end{array}$} & \multirow{2}{*}{$\begin{array}{c}\text { Peak Fuel } \\
\text { Temperature, } \\
{ }^{\circ} \mathrm{C} \\
\end{array}$} \\
\hline & low & high & $\min$ & $\max$ & $\min$ & peak & \\
\hline RERTR-4 & 5.0 & 5.5 & $2 ?$ & $4 ?$ & & & $180 ?$ \\
\hline RERTR-6 & 2.8 & 3.9 & 2.9 & 4.2 & 116 & 175 & $91-151$ \\
\hline RERTR-7A & 2.8 & 7 & 3.5 & 9.0 & 115 & 327 & $113-251$ \\
\hline RERTR-8 & 3.8 & 7.2 & 4.1 & 7.8 & 164 & 296 & \\
\hline RERTR-9A & 3.7 & 7.5 & 4.4 & 8.8 & 241 & 293 & \\
\hline RERTR-9B & 7.2 & 9.3 & 7.3 & 9.5 & 219 & 316 & \\
\hline
\end{tabular}

Note that the time at power for the various experiments was RERTR-4, 230 days; RERTR-6, 109 days; RERTR-7A , 90 days; RERTR-8, 104.7 days; RERTR-9A, 98.1 days ; RERTR-9B, 114days; RERTR-10A, 82 days; and RERTR-10B, 30 days.

\subsection{Post-irradiation Examination Results from the Early Experiments (RERTR-4, RERTR-6 and RERTR-7A)}

Following the limited but encouraging results from the few monolithic fuel samples tested in RERTR-4, the results from the RERTR-6 and -7A demonstrated more completely the fundamental operating characteristics and attributes of U-Mo fuel plates with foil-type fuel meat. ${ }^{19,20,21}$

RERTR-6 provided information that U-7Mo interacted more with the cladding than U-10Mo during both fabrication and irradiation, I also indicated higher swelling in the lower Mo alloy for foils of the same thickness; while swelling in the thicker foils was larger but in proportion to the higher uranium loading. ${ }^{20}$ It was expected that later experiments would show an even greater dependence on alloy composition when higher fission rates and fission densities were employed. 
The thickness of the IL of the fuel and 6061 aluminum cladding is a key differentiator between the two fuel alloys. The IL of the U-7Mo plates was roughly twice that of the U-10Mo plates ( 4-6 $\mu \mathrm{m}$ vs. $\sim 3 \mu \mathrm{m}$, respectively). ${ }^{20}$ Because the IL layers are usually very brittle, it was thought that the IL should be minimized to prevent a potential debonding of the fuel/clad interface if cracks ran along the interface. More pronounced swelling/voids in the IL were also observed in the U-7Mo alloy design and were suspected of being a potential cause of the higher swelling in that design. Figure 2 shows representative bubbles in the interaction layer of a U-10Mo fuel plate.

Swelling of the actual fuel foil does not seem to be much different between the alloy compositions tested. This is supported by the bulk fuel swelling correlations used in modeling efforts. ${ }^{22}$ There is very little difference predicted in the bulk swelling of U-7Mo and U-10Mo at these operating temperatures. More recent models have removed the dependence of Mo concentration.

In addition to the aluminum-clad plates, a Zircaloy-clad U-7Mo plates, fabricated in Argentina, were included in the RERTR-7 test and performed well to relatively low fission density (about half of other plates in the RERTR-7 test due to comparatively low enrichment). The integrity of the fuel/clad interface appeared very stable under irradiation (i.e. the post irradiation examination revealed no particular interface reaction). This result adds to results of later tests using $\mathrm{Zr}$ barriers between fuel and cladding.

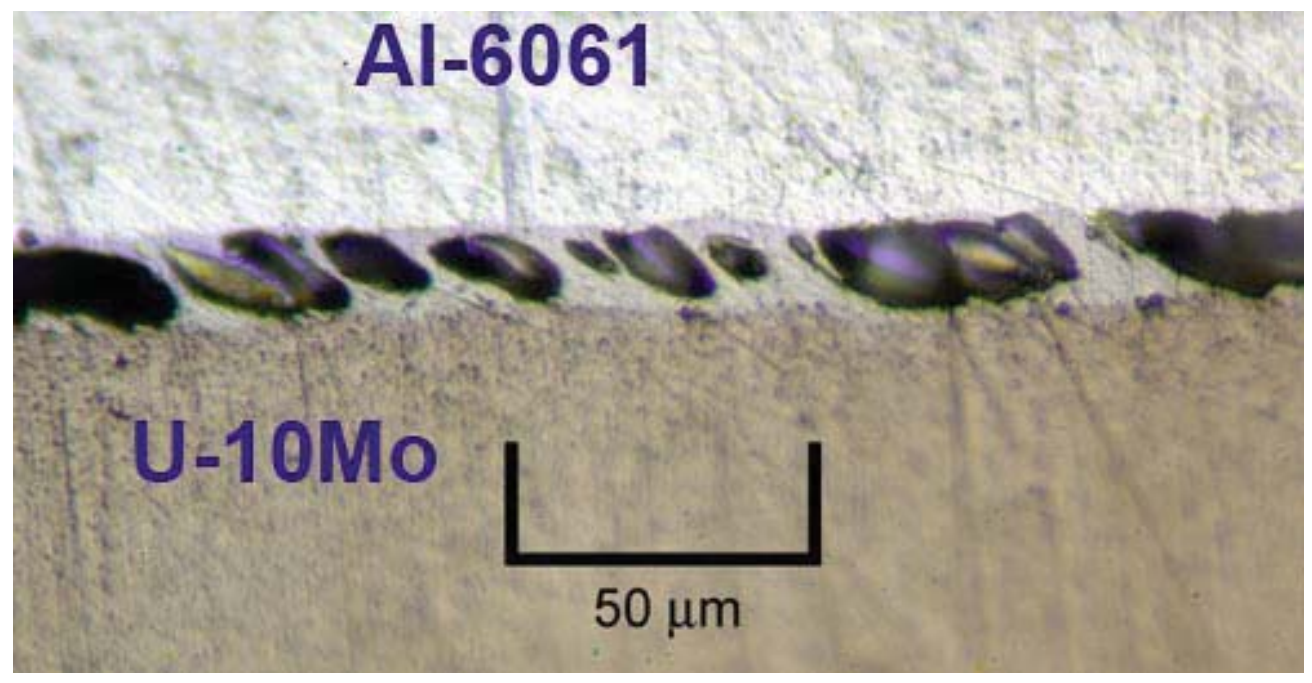

Figure 2. Bubble formation in the interaction layer between a U-10Mo foil and Al-6061.

In addition to the FB plates, the RERTR-7 experiment included fuel plate fabricated by TLPB. In this process silicon is applied to the interface and then hot pressed at a temperature above the Si-Al eutectic temperature of $577^{\circ} \mathrm{C}$ to form a bond between the fuel and cladding. This process inherently produces an IL at the fuel cladding interface. U-10Mo and U-12Mo were successfully fabricated for the RERTR-7 experiment using the TLPB process. The U-12Mo plates appeared to swell less than the U-10Mo alloy, but the only U-10Mo plate bonded by TLPB delaminated during so the comparison was made to U-10Mo plates bonded by FB. The observed debonding/delamination lead to elimination of the TLPB bonding process from future tests.

The fuel/clad interface in plates fabricated using FB in RERTR-7 performed poorly (delamination observed during post irradiation sectioning of fuel plates) but fabrication process improvements were realized that were expected to correct the delamination problem. These improvements were tested in later experiments (RERTR-9). 


\subsection{RERTR-8: Inclusion of Hot Isostatic Pressing}

The RERTR-8 experiment expanded the fabrication options tested for monolithic fuel plates to include foil barriers, a spray-coating barrier of Si-Al (applied to the cladding prior to fabrication), and the HIP bonding process. To reduce swelling and prevent debonding the prevention or minimization of a U-Mo/aluminum IL was sought. This would be done by modifying the IL using Mo concentration in the foil alloy (U-8Mo, U-10Mo and U-12Mo) or by preventing its formation through the use of a barrier. The HIP processing was added to provide another fabrication option with a high reliability, strong bond between the fuel and cladding. Post irradiation examination results from the experiment were recently published. $^{23}$

Swelling and debonding were of particular interest in the post-irradiation examination of the monolithic fuel plates in the test, which also contained dispersion fuel plates. The swelling of the monolithic fuel plates, as measured by plate thickness change, is shown in Figure 3. While the swelling levels are very similar, and trend fairly consistently with the dispersion fuel plates, the lowest Mo concentration alloy, U-8Mo, showed the most swelling. Metallography on a plate with U-12Mo fuel showed no large bubbles/porosity at the fuel/cladding interface, although some smaller, non-uniform bubbles were observed near the high-power edge of the plate (the power varies by a factor of 1.9 across the plate width as one edge faces the ATR core). ${ }^{23}$ This is shown in Figure 4.

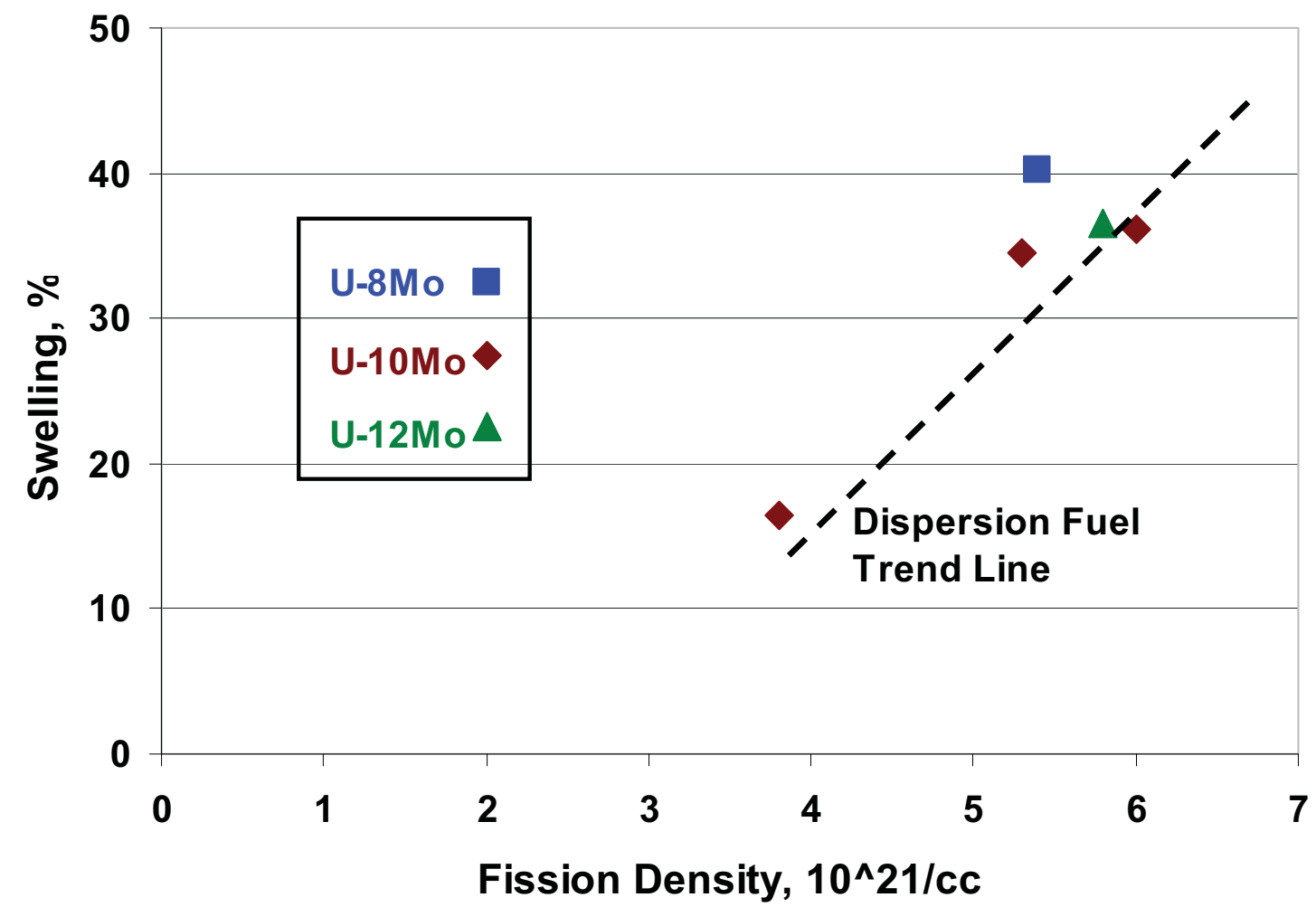

Figure 3. RERTR-8 monolithic fuel swelling as measured by plate thickness change. ${ }^{23}$ 


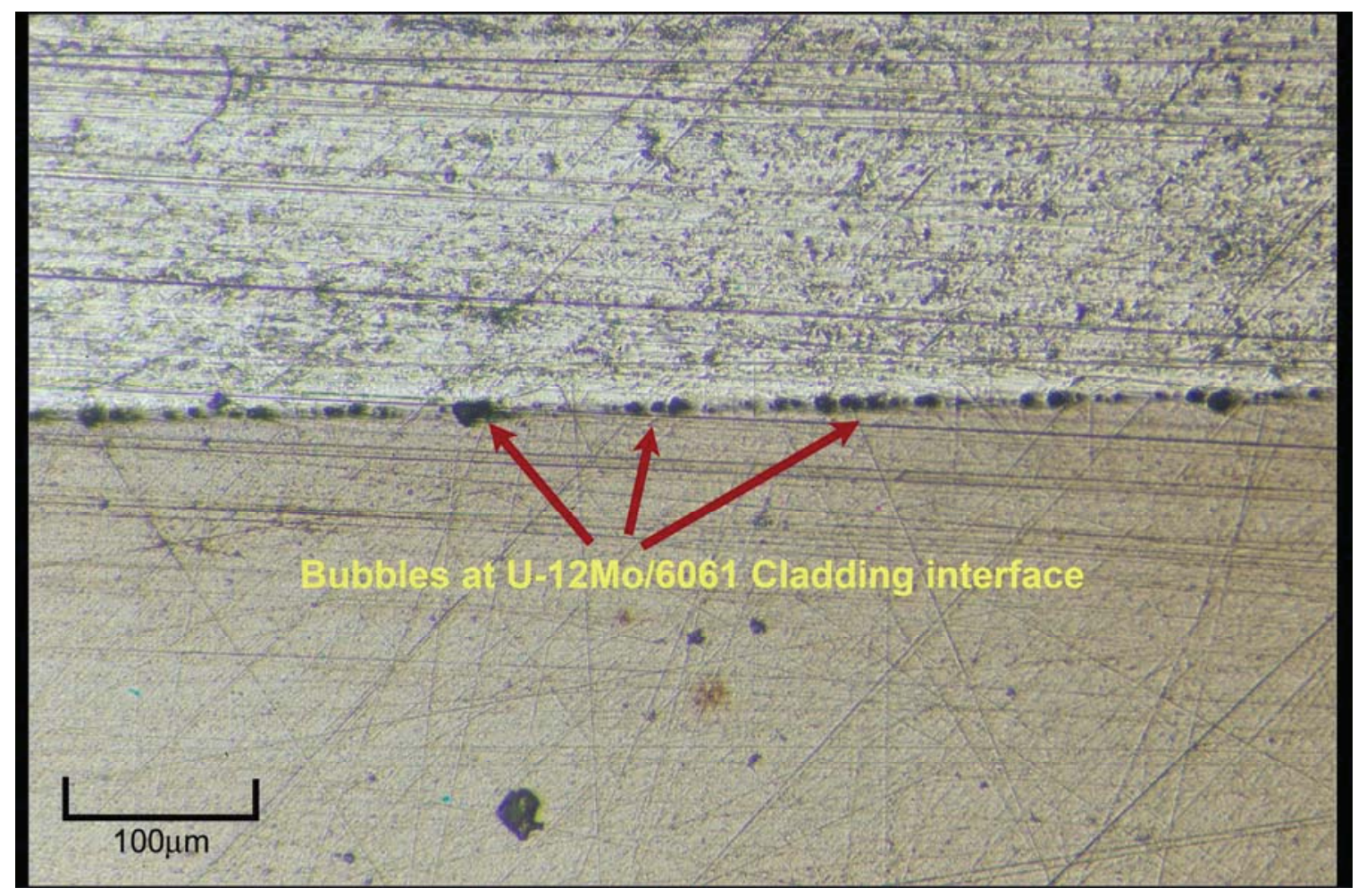

Figure 4. Optical image of metallographic section of monolithic fuel plate from RERTR-8 (U-12Mo, Al-6061 Cladding).

At equivalent fission densities U-10Mo and U-12Mo plates RERTR-7 plates swelled more than the RERTR- 8 plates. ${ }^{24}$ Note, despite the difference in magnification, the much smaller bubbles at the interface in the RERTR- 8 plate in Figure $4\left(\mathrm{f}_{\mathrm{d}} \sim 8.8 \times 10^{21} \mathrm{f} / \mathrm{cm}^{3}\right.$, HIP bonded) compared to those in the interface of the plate from RERTR-7 shown in Figure $2\left(\mathrm{f}_{\mathrm{d}} \sim 8.1 \times 10^{21} \mathrm{f} / \mathrm{cm}^{3}, \mathrm{FB}\right.$ bonded). The swelling was therefore suspected of being very sensitive to the fuel/cladding bonding method which impacted the condition of the interface prior to irradiation. More emphasis was therefore placed upon making the interface and IL formation less dependent upon the fabrication details; the use of fuel/cladding barriers was considered necessary to achieve this goal.

\subsection{The Introduction of Barrier Layers}

Barrier layers were developed to control fuel/cladding interaction and interface degradation during irradiation. Fabrication development efforts were initiated to investigate various methods to construct fuel plates designed with a barrier material. A number of potential barrier materials were studied within the context of the previously developed bonding methods (FB and HIP).

The HIP bonding process had previously been found to provide the strongest bond for as-fabricated test plates (which did not contain barrier layers). ${ }^{25}$ Another detailed study of the interfacial bond between the fuel and clad was performed to evaluate $\mathrm{Zr}, \mathrm{Nb}, \mathrm{Ta}, \mathrm{C}, \mathrm{Si}$, or Ti barriers. ${ }^{26}$ Samples with $\mathrm{Zr}$, Ti and $\mathrm{Nb}$ barriers inserted between the foil and clad prior to HIP bonding demonstrated a strong bond between the barrier layer and the cladding but not between the barrier layer and the fuel. A carbon interface did not bond well to either surface. Roll-bonding the diffusion barrier to the fuel foil prior to the HIP process resulted in a good bond between the fuel, barrier, and cladding. Following these demonstrations $\mathrm{Zr}, \mathrm{Nb}$ and Ti became viable candidates for an interface barrier. Friction bonding was also shown to produce an acceptable bond between the fuel/barrier foil and the cladding. ${ }^{13}$ 


\subsection{RERTR-9 and RERTR-10: Testing of the Primary Design Options}

\subsubsection{RERTR 9}

Additional testing of monolithic fuel plates with improved fuel/cladding interfacial bonds and barrier modified interfaces (that did not collect fission gas bubbles during irradiation) was the focus of the RERTR-9 experience. Fuel plates were fabricated with $\mathrm{Zr}$ and Si enhanced barrier layers and variations on previous FB and HIP fabrication techniques were used to supply the fuel plates.

Although Friction bonding (FB) was found in some of the previous testing to produce insufficient bond strength, a fabrication variation, involving the use of a different tool material (the tool being that which rotates against the surface of the plate to create material flow and bonding), was employed for these tests. The new tool material was shown to produce a significantly stronger as-fabricated fuel/clad bond. ${ }^{13,27,28}$ Both tool materials were used to fabricated test plates for the RERTR-9 experiment.

Because the U-10Mo fuel alloy seemed to provide an optimum balance between fuel fabrication and fuel performance, the RERTR-9 experiment contained only fuel plates using the U-10Mo fuel alloy. Other design variables tested included the addition of silicon to the fuel/clad interaction layer and the insertion of a $\mathrm{Zr}$ diffusion barrier. Silicon is expected to stabilize the IL fission gas behavior much like it did in the U-Mo dispersion fuel system. The silicon was incorporated into the experiment through the insertion of an Al-4043 interface foil ( $5 \%$ silicon) and thermal plasma sprayed Si to the interface between the fuel and cladding prior to bonding.

The RERTR-9 test demonstrated that a number of these solutions for a strong, stable bond were not entirely successful. The FB tool material change did not provide for a more stable bond when tested in-reactor as several plates showed evidence of delaminating during irradiation and sectioning (although none failed during irradiation), one using the standard tool steel and another Anviloy. ${ }^{28}$ Plates with the $\mathrm{Si}$ sprayed and bonded interface also showed a tendency to delaminate at the interface. A thicker spray layer before bonding seemed to promote delaminating; a thinner layer had a stronger bond but a brittle interaction layer was discovered upon post-irradiation examination. ${ }^{28}$

The use of Al-4043, which contains $\sim 5 \mathrm{wt} \% \mathrm{Si}$, was thought to perhaps allow the formation of an IL rich in silicon and as demonstrated in dispersion fuels using a Si-bearing matrix material, one that is resistant to fission gas bubble formation. Examination of a test plate however, showed that the effects of including the Al-4043 intermediate material at the interface showed that the Al-4043 had little effect on bubble formation (see Figure 5). In fact, the plate examined which had Al-4043 at one interface and only Al-6061 clad at the other showed that the bubbles were noticeably larger at the interface with Al-4043 (see Figure 6). ${ }^{28}$ 


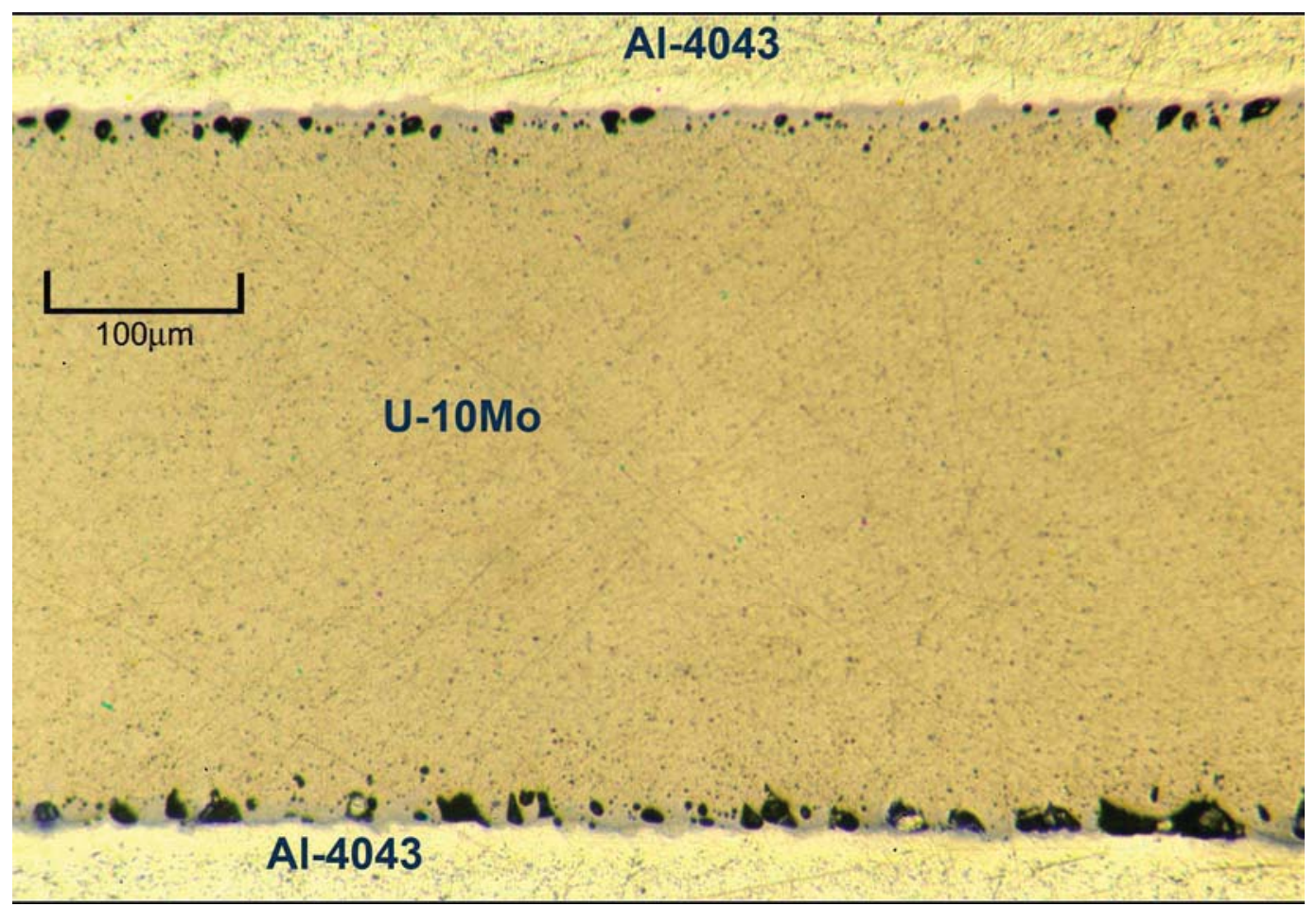

Figure 5. Optical micrograph of RERTR-9 test plate cross-section, which had an inner Al-4043 clad interface.

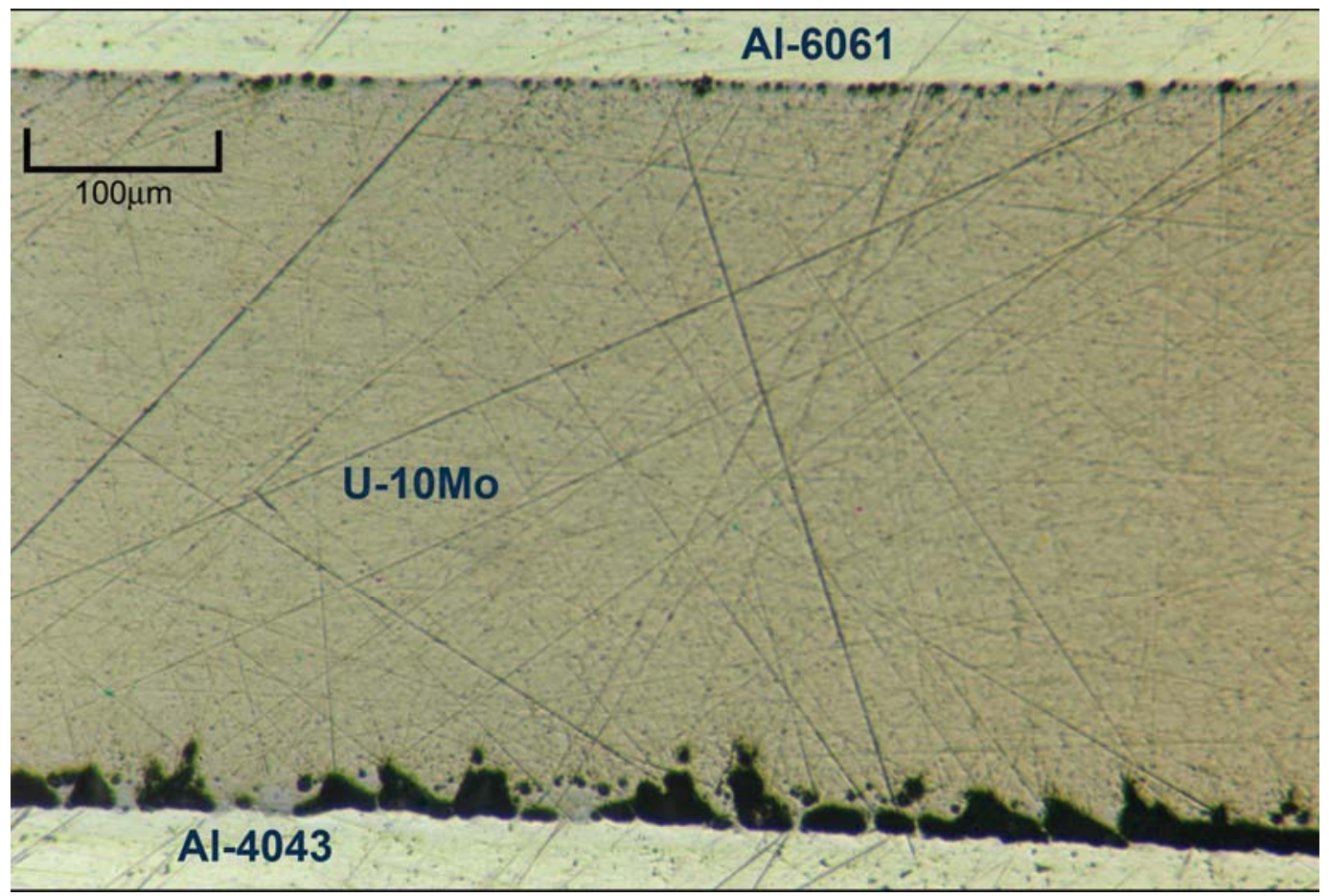

Figure 6. Optical micrograph of RERTR-9 test plate cross-section, which had an Inner Al-4043 clad interface on one surface (lower edge in photo) and Al-6061 on the other. 
One interface design variable that seemed to perform very well was the addition of a $\mathrm{Zr}$ foil between the fuel and cladding. The $\mathrm{Zr}$ foil was applied by hot co-rolling with the fuel foil prior to the HIP process. Figure 7 shows an optical micrograph of the Al-6061/Zr/fuel/Zr/Al-6061 interfaces following irradiation. The bond remained intact (on both the fuel and clad side) and bubbles did not appear at the interface.

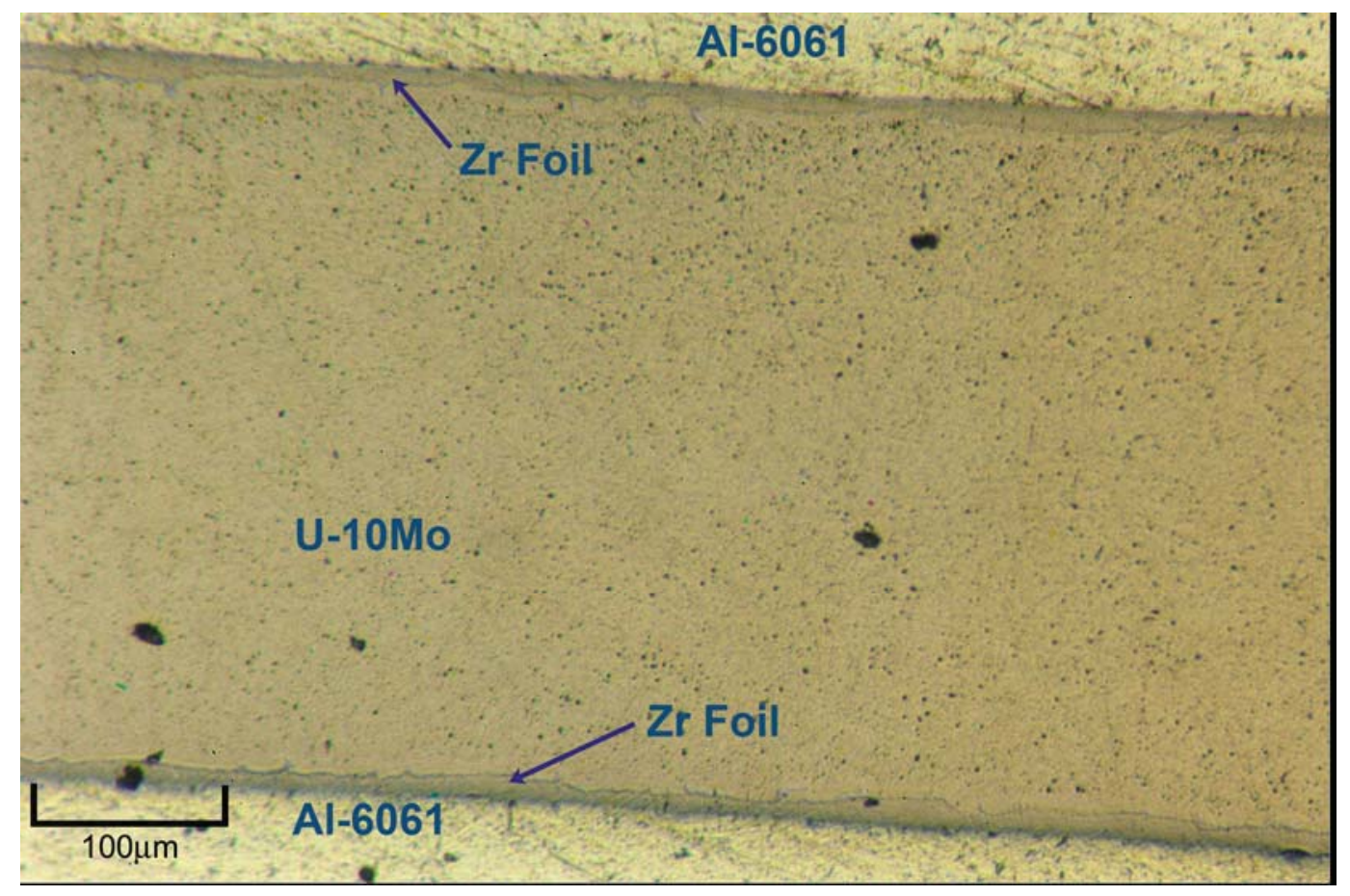

Figure 7. Optical micrograph of an RERTR-9 fuel plate cross-section ('cold' side).

The hot side of the fuel plate width (Figure 8) developed cracking in the fuel, which was likely caused by cooling the plate on shut-down of the reactor or cutting of the fuel plate. If the interfaces were weak or very brittle, or if the bond between the layer and the fuel or $\mathrm{Zr}$ foil were weak, these cracks would likely have propagated along the interface. Figure 8 indicates that they did not propagate through the layer or along the interface.

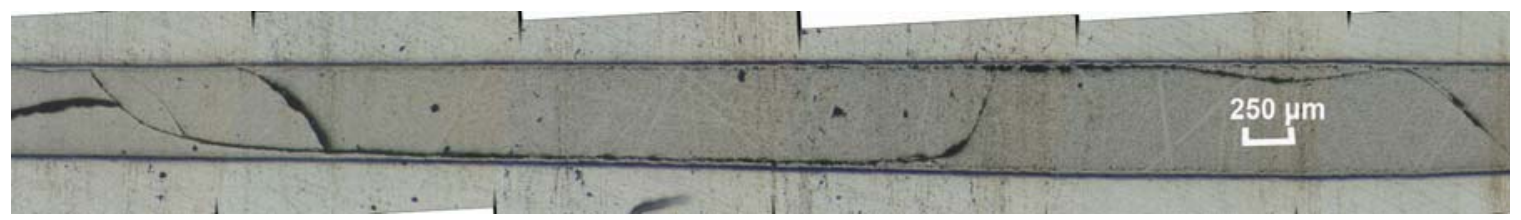

Figure 8. Optical micrograph of an RERTR-9 fuel plate cross-section ('hot' side). The fuel foil has cracked but the cracks do not propagate along or through the fuel/Zr boundary.

The HIPed U-10Zr plate with a $\mathrm{Zr}$ foil barrier seemed to perform reliably with a stable fuel/cladding interface. The conditions for this fuel plate in the RERTR-9 test were very challenging, with an average heat flux near $300 \mathrm{~W} / \mathrm{cm}^{2}$ and a fission density of $\sim 7.5 \times 10^{21}$ fissions $/ \mathrm{cm}^{3}$; two plates of this design were tested with consistent results. 


\subsubsection{RERTR-10A,B}

The RERTR-10 experiment was split into two halves where the RERTR-10A experiment contained U-10Mo-based monolithic fuel plates that were all bonded using HIP and the RERTR-10B experiment contained monolithic plates bonded using FB. Zirconium foil interlayers were included as variables in both tests. A niobium foil barrier was tested in the RERTR-10B test. Several fuel plates were also allocated to investigate the use of $\mathrm{Si}$ at the fuel/cladding boundary. The variations in thermal spray included pure $\mathrm{Si}$, and $1 \%, 2 \%, 3.5 \%, 5 \%$, and $12 \% \mathrm{Si}$ in Al. For the $12 \% \mathrm{Si}$ coating a pre-reacted eutectic material was used; the other coatings were blends of $\mathrm{Al}$ and Si. On several plates spray coatings of $25 \mu \mathrm{m}$ and $51 \mu \mathrm{m}$ (one on either side of the same plate) were applied to test the effect of the thickness of the coating in addition to the composition. Fuel foils of standard thickness $(0.25 \mathrm{~mm})$ and double thickness $(0.51 \mathrm{~mm})$ were included in the fuel plates containing $\mathrm{Zr}$ foils, two of each in RERTR-10A.

At this point, only the plates from RERTR-10A (plates with HIP bonding) have been examined. Figure 9 shows the average swelling of a plate as measured by fuel plate thickness measurements (sixteen points laid out in a 3 (width) $\times 6$ (length) grid on the plate). Near the ends of the plates there was often a thick area as caused by creep of the fuel as it experiences multi-dimensional restraint at the sealed ends of the mini-plates; these data points were disregarded in making the averages as shown in Figure 9.

With the exception of the $12 \%$ eutectic coating, the others using a thermal spray showed instances of significant increase in thickness, with delamination likely contributing in each case. The plates using the $\mathrm{Zr}$ foil barrier showed low swelling. Although not labeled, the two plates showing the lower swelling were the two with thicker fuel.

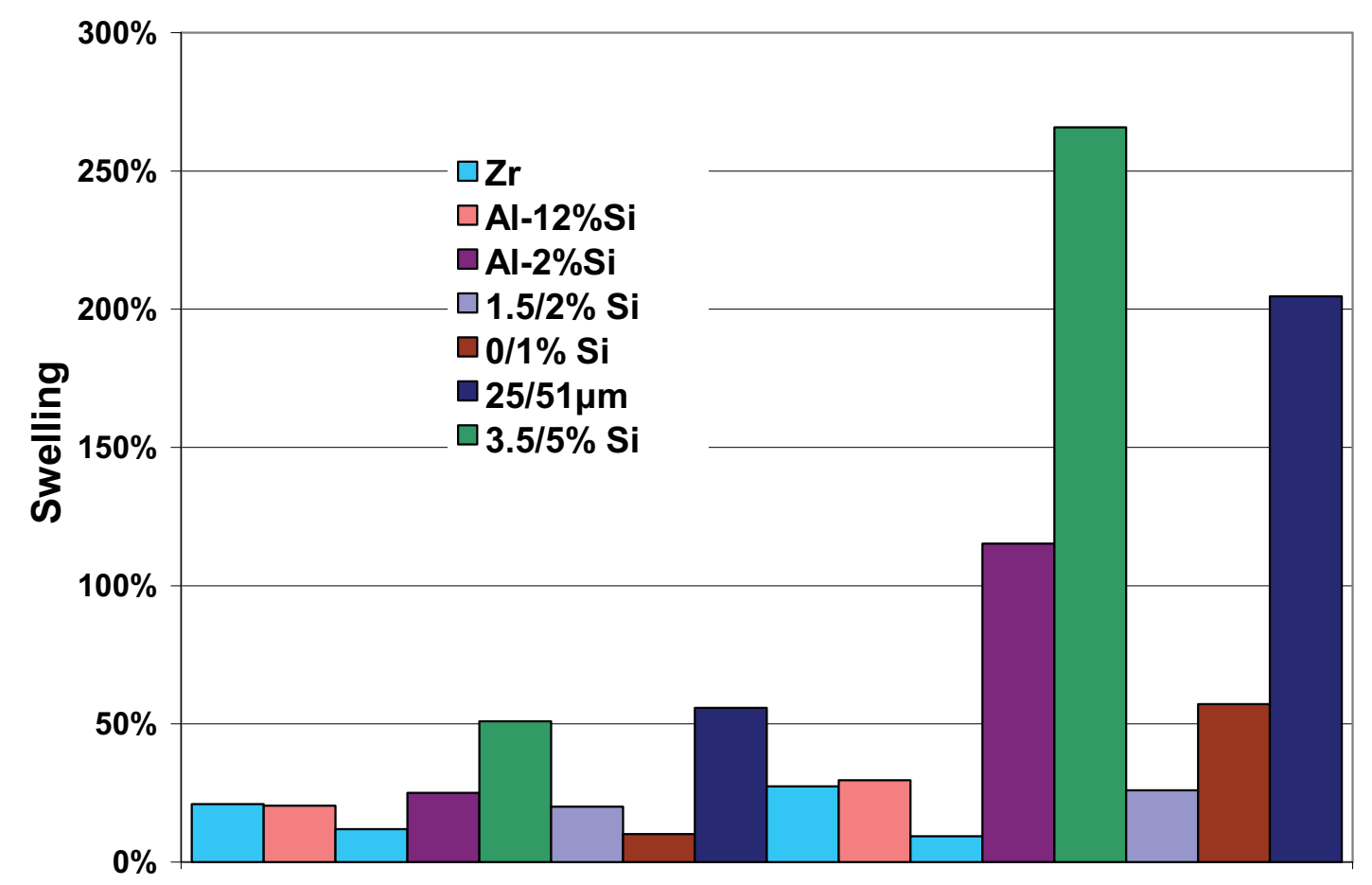

Figure 9. Average swelling (thickness increase) of a fuel plate. Variables are shown in legend. Those labels indicating two variables, e.g., $1.5 / 2 \% \mathrm{Si}$, one relates to the coating on one side of the plate and the other for the opposite side. 
The metallography showed that the thermal sprayed plates typically had areas of delamination, or, for some cases, nearly complete unbond. The implications are that the silicon enhanced interaction layer may produce fission gas bubble resistant layers but the fuel/clad bond still degrades during irradiation and ultimately tends toward delamination under extreme conditions.

A plate with co-rolled $\mathrm{Zr}$ foil was also examined. The examination demonstrated that the bond of fuel to $\mathrm{Zr}$ foil and $\mathrm{Zr}$ foil to Al-6061 cladding remained intact. Figure 10 shows an area near the fuel/Zr barrier after irradiation to very high burnup. This image shows an accumulation of fission gas bubbles (significantly larger than those observed in the bulk of the fuel). Coalescence of these bubbles into a large defect may be the ultimate performance limiting feature in the $\mathrm{Zr}$ barrier fuel design. However, these bubbles are not observed until the fuel reaches fission densities much higher than are possible in an LEU based fuel and coalescence into a meaningful defect has not been observed to this point.

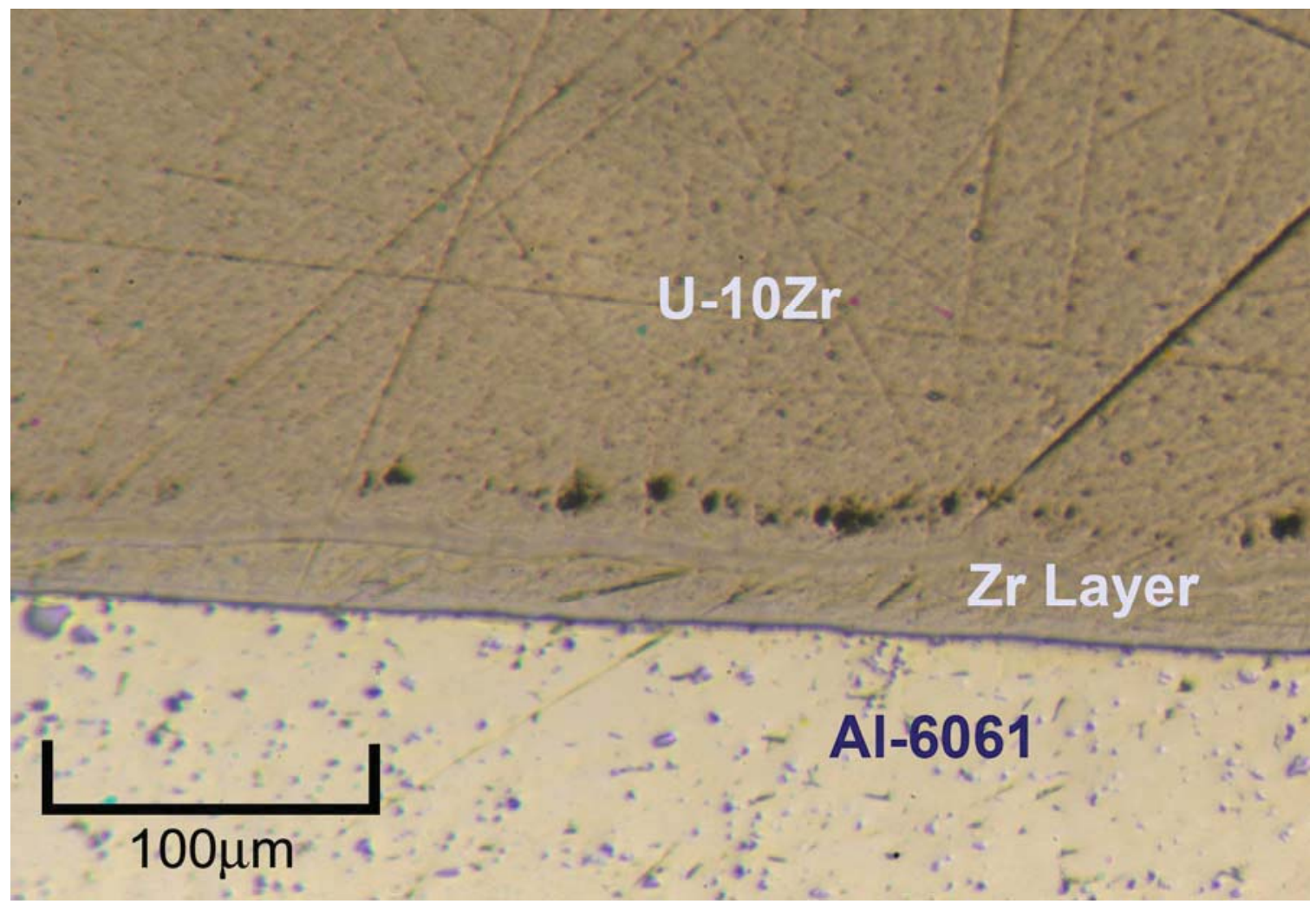

Figure 10. Optical metallography of an RERTR-10A fuel plate, co-rolled with $\mathrm{Zr}$ foil barriers and HIP processed. Only a small amount of porosity/bubble formation is visible at the $\mathrm{Zr}$-fuel boundary.

The RERTR-10A results indicated the in-reactor performance of the thermal sprayed fuel plates were not satisfactory. The plates fabricated with $\mathrm{Zr}$ foil barriers performed well. The HIP bonding process, combined with the $\mathrm{Zr}$-foil barrier design, seems to work well in producing a good, dependable bond. The friction bonded plates in RERTR-10B have yet to be examined, but the RERTR-9 results indicate that bonding process parameters are likely to be less significant than interface composition. 


\subsection{AFIF-2 and AFIF-3}

Additional testing was conducted at the prototypic scale $(50 \mathrm{~mm} \times 600 \mathrm{~mm}$ fuel plates $)$ to ensure that phenomena observed at the mini-plate scale are representative of those expected for fuel plates ultimately placed in service. Two irradiation campaigns, AFIP-2 and AFIP-3, were conducted for this purpose. Both tests included a plate design with a silicon enhanced fuel/clad interface and a zirconium diffusion barrier. The AFIP-2 test was constructed by FB and the AFIP-3 test by HIP. All four plates showed acceptable dimensional stability (i.e., no plate buckling) in spite of prototypic burnup gradients. Fuel plate thickness measurements following irradiation showed that the overall fuel swelling appeared more regular in the $\mathrm{Zr}$ diffusion barrier fuel plates in both cases than the silicon enhanced fuel plates. 


\section{DISCUSSION}

Preparation of a testing program to produce the optimum design for monolithic, high fuel density RERTR fuel plates has been a somewhat serial process, relying on research and testing into fabrication processes and results of previous success/failures of other RERTR tests to guide the future research. The in-reactor testing process, however, has a long lead time and the results of one test may not have full affect on the design of a future test until after a few generations of tests have already been completed. In parallel with the in-reactor testing efforts, and fabrication development, a modeling effort has begun to demonstrate that prediction of fuel performance is possible. ${ }^{29}$ The results of all of these efforts are combined to enable down-selection of design variables. With a sufficient number of successful choices the addition of new design choices can be held to a minimum, and back-up options selected.

Selection of design variables then allows a program focused upon the qualification of the fuel, including testing and modeling, to begin. The RERTR tests described in this report have been used to evaluate a wide variety of design variables and have produced results that indicate which fuel design warrant further testing and which should be eliminated.

The in-reactor testing program (RERTR-4, 6, 7, 8, 9, and 10) that has currently been examined has shown the following:

1. Alloy U-10Mo seems to have less swelling under conditions similar to that to which U-7,8Mo fuel has been tested. The difference is not sufficient to eliminate the alloys with less molybdenum, and the alloys with less Mo can be attractive if higher uranium density is required to meet nuclear performance needs. However, other factors are also influential in choosing the optimum alloy.

One of these is that observations made of as-fabricated plates, following the HIP step in the fabrication sequence, has shown that at HIP processing temperatures $\left(\geq 550{ }^{\circ} \mathrm{C}\right)$ very thin interaction layers can form between the $\mathrm{Zr}$ foil and the U-Mo fuel. ${ }^{30}$ The TEM examination identified at least eight layers. Four represented the three original materials including the uranium that had transformed to the alpha phase. The other four were layers of intermetallic materials formed by the interaction of the original three resulting from the bonding treatment. Interaction between the $\mathrm{Zr}$ foil and the Al-6061 cladding produce $\mathrm{Al}_{3} \mathrm{Zr}_{4}$ next to the $\mathrm{Zr}$ and $\mathrm{AlZr}$ next to the cladding. Both Mo and $\mathrm{U}$ are scavenged from the original fuel matrix in the interaction process between fuel and $\mathrm{Zr}$ foil and the result is the formation of a thin layer of $\mathrm{Mo}_{2} \mathrm{Zr}$ next to the fuel, and a $\mathrm{U}-2 \mathrm{Zr}$ layer on the $\mathrm{Zr}$ foil side of the interface. The potentially troublesome issue is that some $\alpha-U$ appears in the fuel at the interface with the $\mathrm{Mo}_{2} \mathrm{Zr}$ layer.

The concentration of Mo in U-7,8Mo is low enough that Mo depletion near the $\mathrm{Zr}$ layer may lead to destabilization of the $\gamma$-U during irradiation. It is well known that the conversion $\gamma-U$ to $\alpha-U$ will result in significant increase in fuel swelling. The additional margin to Mo depletion provided by the use of U-10Mo is therefore desirable. Moreover, the interaction with the $\mathrm{Zr}$ layer could potentially create a larger amount of $\alpha-\mathrm{U}$ in the fuel foil than would appear in the U-10Mo foil.

2. Bonding techniques including hot isostatic pressing (after roll bonding of $\mathrm{Zr}$ clad foils), friction bonding and transient liquid phase bonding (spraying the fuel/cladding interface with Al-Si alloys before bonding with HIP or FB) were shown to all be successful in some instances. The quality and therefore the success of latter two, FB and TLPB, however, were too dependent upon fabrication variables that were difficult to control and delamination between fuel and cladding was frequently observed as a result.

3. Fuel/cladding interface treatments including application of aluminum alloys containing Si and applying barrier materials such as $\mathrm{Zr}$ and $\mathrm{Nb}$ were used to stabilize the fuel/clad interface layer (chemically and mechanically) and therefore the potential for interface separation (delamination). The 
$\mathrm{Zr}$ foil barrier, cold-rolled to the fuel prior to HIP bonding, proved very successful as the interface showed very little interaction and retained a strong bond. 


\section{CONCLUSIONS}

The RERTR experiments performed in the Advanced Test Reactor (ATR), as well as fabrication research and development, have been used to make choices as to which design variables associated with monolithic fuel plates merit further testing and qualification. This report reviewed those variables that were tested in the ATR and highlighted the results that impacted a variable positively or resulted in it being eliminated as a choice. Although the fuel alloys with lower Mo concentration performed nearly as well as those with Mo concentrations of $10 \mathrm{wt} \%$ and above, U-10Mo is the alloy of choice because of its increased phase stability ( $\gamma$ phase) which may reduce swelling and perhaps produce a more stable fuel/cladding interface. The U-10Mo alloy also seems to be an optimal composition for fabrication processes as it has shown excellent rolling properties and is resistant to decomposition during exposure to elevated temperatures. There were indications of slightly lower swelling in plates with U-10 or $12 \mathrm{Mo}$, and there is a potential interaction (interdiffusion) effect when $\mathrm{Zr}$ is layered between the fuel and the cladding (Mo loss) that further reduces phase stability.

A Zr foil barrier has been chosen as a means to prevent significant fuel/cladding interaction that could cause fission gas bubbles at the boundary and potentially mechanical destabilization of the interface, ultimately leading to delamination.

The recommended fabrication method used to bond the layers (U-10Mo, $\mathrm{Zr}$ and Al-6061) of the plate together consist of the hot isostatic pressing (HIP) of the cladding onto $\mathrm{Zr}$ coated foils that have been fabricated by hot co-rolling. Spraying with aluminum-silicon alloys or mixtures has not proven to consistently produce stable bonds that would survive fuel operation. Fuel plate fabricated by friction bonding performed fairly well but process parameters are not as well understood and the barriers to commercial implementation (due to technological maturity) are greater than the HIP process.

A U-10Mo monolithic fuel plate, using a $\mathrm{Zr}$ foil barrier between fuel and cladding, and fabricated by co-rolling the layers and then bonding by a HIP process, is the fuel design of choice. This fuel design will therefore be carried forward into qualification testing by the RERTR Advanced Fuel Development Program. 


\section{REFERENCES}

1. C. R. Clark, G. C. Knighton, M. K. Meyer and G. L. Hofman, "Monolithic Fuel Plate Development at Argonne National Laboratory," RERTR 2003, $25^{\text {th }}$ International Meeting on Reduced Enrichment for Research and Test Reactors (RERTR), October 5-10, 2003, Chicago, Il, U.S.A.

2. J. R. Phillips and A. Travelli, "Acceleration of the RERTR Program: Scope, Status and Plans," ENS RRFM 2003, 7th International Topical Meeting on Research Reactor Fuel Management, 2003; Aix En Provence, France.

3. J. L. Snelgrove, P. Lemoine, P. Adelfang and Arkhangelsky, "Qualification and Licensing of U-Mo Fuel," ENS RRFM 2003, 7th International Topical Meeting on Research Reactor Fuel Management, 2003; Aix En Provence, France.

4. L. S. Castleman, "Layer Growth during Interdiffusion in the Aluminum-Uranium Alloy System," J. of Nuclear Materials, v. 3, No. 1 (1961) p. 1-15.

5. H. J. Ryu, Y. S. Kim and G. L. Hofman, "Amorphization of the Interaction Products in U-Mo/Al Dispersion Fuel During Irradiation," J. of Nuclear Materials, v. 385 (2009) p.623-628.

6. J. Gan, D. D. Keiser, Jr., D. M. Wachs, A. B. Robinson, B. D. Miller and T. R. Allen, "TEM Characterization of Irradiated RERTR Dispersion Fuel," ENS RRFM 2009, 13th International Topical Meeting on Research Reactor Fuel Management, 2009; Vienna, Austria.

7. D. M. Wachs, "RERTR Fuel Development and Qualification Plan,” INL/EXT-05-01017, Rev. 4 (2009).

8. C. R. Clark and R. J. Briggs, "Development of a Monolithic Research Reactor Fuel Type at Argonne National Laboratory,"

9. C. R. Clark, S. L. Hayes, M. K. Meyer, G. L. Hofman and J. L. Snelgrove, "Update on Monolithic and Dispersion Fuel Development," ENS RRFM 2004, 8th International Topical Meeting on Research Reactor Fuel Management, March 21-24, 2004; Munich, Germany.

10. C. R. Clark, N. P. Hallinan, J. F. Jue, D. D. Keiser and J. M. Wight, "Monolithic Fuel Fabrication Process Development," ENS RRFM 2006, 10th International Topical Meeting on Research Reactor Fuel Management, April 30-May 3, 2006; Sofia, Bulgaria.

11. C. R. Clark, J. F. Jue, G. A. Moore, N. P. Hallinan, and B. H. Park, "Update on Monolithic Fuel Fabrication Methods," RERTR 2006, 28th International Meeting on Reduced Enrichment for Research and test Reactors, Cape Town, South Africa.

12. G. A. Moore, F. J. Rice, N. E. Woolstenhulme, W. D. Swank, D. C. Haggard, J. Jue, B. H. Park, S. E. Steffler, N. P. Hallinan, M. D. Chapple and D. E. Burkes, "Monolithic Fuel Fabrication Process Development at the Idaho National Laboratory," RERTR 2008, 30th International Meeting on Reduced Enrichment for Research and test Reactors, October 5-9, 2008, Washington, D.C., U.S.A.

13. D. E. Burkes, N. P. Hallinen, J. M. Wight and M. D. Chapple, "Update on Friction Bonding of Monolithic U-Mo Fuel Plates," "RERTR 2007, 27th International Meeting on Reduced Enrichment for Research and test Reactors, September 24-27, 2007, Prague, Czech Republic.

14. K. H. Kim, D. B. Lee, S. J. Oh, C. K. Kim, and D. S. Sohn, "Fabrication and Characterization of U-Mo Foils for a Monolithic Fuel by Cooling-Roll Casting Method," ENS RRFM 2004, 8th International Topical Meeting on Research Reactor Fuel Management, March 21-24, 2004; Munich, Germany. 
15. E. E. Pasqualini, "Monolithic UMo Nuclear Fuel Plates with Non-Aluminum Cladding," ENS RRFM 2008, 12th International Topical Meeting on Research Reactor Fuel Management, March 2-5, 2008; Hamburg, Germany.

16. "Uranium-Molybdenum Fuel Foil Fabrication Development Activities at the Y-12 National Security Complex," RERTR 2006, 28th International Meeting on Reduced Enrichment for Research and Test Reactors, Cape Town, South Africa.

17. T. R. Muth and B. Oakley, "Production of Depleted U-10Wt\% Mo Foils," RERTR 2008, 30th International Meeting on Reduced Enrichment for Research and test Reactors, October 5-9, 2008, Washington, D.C., U.S.A.

18. G. L. Hofman, J. L. Snelgrove, S. L. Hayes, M. K. Meyer and C. R. Clark, "Progress in Postirradiation Examination and Analysis of Low-enriched U-Mo Research Reactor Fuels," ENS RRFM 2003, 7th International Topical Meeting on Research Reactor Fuel Management, 2003; Aix En Provence, France.

19. M. R. Finlay, D. M. Wachs, A. B. Robinson and G. L. Hofman, "Post Irradiation Examination of Monolithic Mini-fuel Plates from RERTR-6 \& 7," ENS RRFM 2007, 11th International Topical Meeting on Research Reactor Fuel Management, 2007; Lyon, France.

20. M. R. Finlay, D. M. Wachs and G. L. Hofman, "Post Irradiation Examination of Monolithic Mini Fuel Plates from RERTR-6," RERTR 2006, 28th International Meeting on Reduced Enrichment for Research and test Reactors, Cape Town, South Africa.

21. D. D. Keiser, Jr., A. B. Robinson and M. R. Finlay, "Observations Derived from the Characterization of Monolithic Fuel Plates Irradiated as Part of the RERTR-6 Experiment," RERTR 2007, 27th International Meeting on Reduced Enrichment for Research and test Reactors, September 24-27, 2007, Prague, Czech Republic.

22. S. L. Hayes, G. L. Hofman, M. K. Meyer, J. Rest and J. L. Snelgrove, "Modeling of High-density U-Mo Dispersion Fuel Plate Performance," RERTR 2002, 22nd International Meeting on Reduced Enrichment for Research and test Reactors, November 3-8, 2002, San Carlos de Bariloche, Argentina.

23. A. B. Robinson, "RERTR-8 PIE Letter Report: Compilation of Post-irradiation Examination Data Collected During the RERTR-8 Experiment Campaign," INL/EXT-09-XXXX (Draft), 2009.

24. A. B. Robinson and M. R. Finlay, "RERTR-7 Post-irradiation examination (PIE) Letter report," INL/EXT-07-13271, 2007.

25. D. E. Burkes, D. D. Keiser, Jr., D. M. Wachs, J. S. Larson and M. D. Chapple, "Characterization of Monolithic Fuel Foil Properties and Bond Strength,", ENS RRFM 2007, 11th International Topical Meeting on Research Reactor Fuel Management, 2007; Lyon, France.

26. D. D. Keiser, Jr., J. F. Jue and D. E. Burkes, "Characterization and Testing of Monolithic RERTR Fuel Plates," ENS RRFM 2007, 11th International Topical Meeting on Research Reactor Fuel Management, 2007; Lyon, France.

27. D. D. Keiser, Jr., J. F. Jue and D. E. Burkes, "Characterization and Testing of Monolithic RERTR Fuel Plates," ENS RRFM 2007, 11th International Topical Meeting on Research Reactor Fuel Management, 2007; Lyon, France.

28. A. B. Robinson, D. M. Wachs, D. E. Burkes and D. D. Keiser, "US RERTR Fuel Development Post Irradiation Examination Results," RERTR 2008, 30th International Meeting on Reduced Enrichment for Research and test Reactors, October 5-9, 2008, Washington, D.C., U.S.A.

29. Y. S. Kim, G. L. Hofman, P. G. Medvedev, G. V. Shvlyakov, A. B. Robinson and H. J. Ryu, "Post Irradiation Analysis and Performance Modeling of Dispersion and U-Mo Monolithic Fuels," RERTR 
2007, 30th International Meeting on Reduced Enrichment for Research and test Reactors, September 23-27, 2007, Prague, Czech Republic.

30. Y. Sohn, unpublished research. 